\title{
Randomized Controlled Trial of a Brief Cognitive-Behavioral Strategies Intervention for the Pain, Fatigue, and Sleep Disturbance Symptom Cluster in Advanced Cancer
}

\author{
Kristine Kwekkeboom ${ }^{1}$, Yingzi Zhang ${ }^{1}$, Toby Campbell ${ }^{1,2}$, Christopher L. Coe ${ }^{3}$, Erin \\ Costanzo $^{4}$, Ronald C. Serlin ${ }^{5}$, and Sandra Ward ${ }^{1}$ \\ 1.School of Nursing, University of Wisconsin-Madison \\ 2.Department of Medicine, School of Medicine and Public Health, University of Wisconsin- \\ Madison \\ 3.Department of Psychology, College of Letters and Science, University of Wisconsin-Madison \\ 4.Department of Psychiatry, School of Medicine and Public Health, University of Wisconsin- \\ Madison \\ 5.Department of Educational Psychology, School of Education, University of Wisconsin-Madison
}

\section{Abstract}

Objective: Patients receiving treatment for advanced cancer suffer significant symptom burden, including co-occurring pain, fatigue, and sleep disturbance. There is limited evidence for effective interventions targeting this common symptom cluster.

Methods: A randomized controlled trial of a brief cognitive-behavioral strategies (CBS) intervention was conducted. A sample of 164 patients with advanced cancer receiving chemotherapy practiced imagery, relaxation and distraction exercises or listened to cancer education recordings (attention-control) to manage co-occurring pain, fatigue, and sleep disturbance over a 9-week period. Symptom cluster severity, distress, and interference with daily life were measured at baseline and 3-, 6-, and 9-weeks. We also evaluated the moderating influence of imaging ability and number of concurrent symptoms, and mediating effects of changes in stress, anxiety, outcome expectancy, and perceived control over symptoms.

Results: Compared to the cancer education condition, participants receiving the CBS intervention reported less symptom cluster distress at week 6 (M=1.82 vs. 2.15 on a $0-4$ scale, $p$ $<.05)$. No other group differences were statistically significant. The number of concurrent symptoms moderated the intervention effect on symptom cluster interference. Changes in stress, outcome expectancy and perceived control mediated the extent of intervention effects on symptom outcomes, primarily at weeks 6 and 9 .

Conclusions: The brief CBS intervention had limited effects in this trial. However, findings regarding potential mediators affirm hypothesized mechanisms and provide insight into ways to

The authors have no conflicts of interest to declare. 
strengthen future interventions to reduce the suffering associated with co-occurring pain, fatigue, and sleep disturbance.

\section{Background}

Pain, fatigue, and sleep disturbance are among the most common cancer symptoms, reported by nearly half of patients with advanced cancer. ${ }^{1-2}$ Their co-occurrence has been described as a symptom cluster, which results in diminished functional status and poor quality of life. 3-6 The symptoms may present simultaneously or emerge as a cascade, and may be caused by the malignancy, cancer treatments, symptom management strategies (e.g., effects of opioid analgesics), or neuro-inflammatory dysregulation. ${ }^{7-9}$ Although patients with advanced cancer suffer disproportionately, investigators often select samples with early stage disease, that have greater capacity to comply with study procedures, and lower attrition.

While many investigators have conducted analyses to identify symptom clusters, few have tested interventions to manage a defined symptom cluster, and rarely have interventions been developed to fit the limited capacities and shorter prognosis of patients with advanced disease. ${ }^{7}$ We identified seven studies reporting tests of interventions targeting a specific cancer symptom cluster. ${ }^{10-16}$ Five targeted the pain, fatigue, sleep disturbance symptom cluster. All were feasibility or pilot trials and found beneficial effects of cognitive-behavioral strategies $^{11-12}$, massage ${ }^{13-14}$ or acupressure ${ }^{15}$.

The current study is the first full-scale randomized controlled trial (RCT) of an intervention targeting the pain, fatigue, and sleep disturbance symptom cluster. Using evidence from studies of single symptoms, guidelines for managing cancer pain ${ }^{17-18}$, fatigue ${ }^{19}$, and sleep disturbance ${ }^{20-21}$ each recommend cognitive-behavioral strategies (CBS) including imagery, relaxation, and distraction. Symptom-focused imagery involves creating and manipulating thoughts and images to change symptom perception. Relaxation strategies may relieve emotional stress and physical tension that intensify symptom perceptions. All three strategies may provide a source of pleasant distraction that modifies attentional capacity for symptoms. In addition, rationale provided during training may counter commonly held beliefs that cancer symptoms cannot be managed, raise expectations for symptom improvement, and facilitate patients' ability to actively control their symptom experience. ${ }^{22-23}$ We hypothesized that such strategies could be effective in simultaneously managing the clustered symptoms.

Preliminary evidence supports the use of imagery, relaxation, and distraction in treating the cancer pain, fatigue, and sleep disturbance symptom cluster. In a feasibility trial, we demonstrated that patients with advanced cancer were willing to use the intervention and could complete study procedures; they perceived symptom improvement and reported significant reductions in pain, fatigue and sleep disturbance after using CBS. ${ }^{11}$ In a subsequent pilot RCT, we demonstrated reduced symptom cluster severity among patients who used the strategies for 2 weeks as compared to usual care. ${ }^{12}$ Here, we report an efficacy trial of the CBS intervention in a larger cohort. Based on previous research, we tested two proposed moderator variables, imaging ability and concurrent symptoms. ${ }^{24}$ Persons with lower aptitude for creating and experiencing visual images (imaging ability) may have 
limited capacity to benefit from imagery interventions. ${ }^{24}$ Patients with many concurrent symptoms may be too burdened to effectively focus and mentally engage in imagery or relaxation exercises. ${ }^{25}$

Purposes of this study were (1) to test the efficacy of a brief CBS intervention in patients with advanced cancer experiencing the pain, fatigue, and sleep disturbance symptom cluster, and (2) to explore moderators and mediators of intervention effects. We hypothesized that participants who received the CBS intervention would report less symptom cluster severity, distress, and interference than those who received an attention-control condition. Further, we hypothesized that imaging ability and number of concurrent symptoms would moderate intervention effects such that participants with better imaging ability and fewer concurrent symptoms would report less symptom cluster severity, distress, and interference after the CBS intervention than participants with poorer imaging ability or more concurrent symptoms. Finally, we hypothesized that benefits of the intervention would be mediated by improvements in stress, anxiety, outcome expectations, and perceived control over symptoms.

\section{Methods}

\section{Design}

We tested the CBS intervention in a 2-group (1:1 CBS intervention, cancer education) RCT, with stratification by recruitment site, diagnosis, gender, and chemotherapy cycle length.

Participants used the assigned strategies for 9 weeks, with the primary outcomes measured at 3-weeks, and follow-up assessments at 6-, and 9-weeks to explore continued use of intervention strategies and cumulative practice effects. (ClinicalTrials.gov Identifier: NCT00946803)

\section{Sample/Setting}

Participants were $\geq 18$ years old, diagnosed with metastatic or recurrent solid tumor cancers, and receiving outpatient chemotherapy. Eligible patients reported pain, fatigue, and sleep disturbance in the past week, with "worst" severity rated $\geq 3$ [0-10 numeric rating scale (NRS)] for at least two of the three symptoms. Patients with severe neuropathic pain (score $\geq$ 4, ID Pain questionnaire ${ }^{26}$ ), acute post-operative pain, and those hospitalized for psychiatric reasons within the last 3 months were excluded. After 7 months of recruitment ( $n=15$ enrolled), we expanded initial eligibility criteria from 3-week IV cytotoxic chemotherapy regimens to include regimens of any type or length. A priori power analysis based on pilot data $^{12}$ indicated a sample of $\mathrm{N}=128$ (64 per group) would provide power of .8 to detect a medium-sized intervention effect on symptom cluster severity, distress, and interference with daily life, and medium effects in mediation and moderation analyses. Recruitment stopped when 64 persons/group provided week-3 data.

Patients were recruited between December 2013 and November 2016 from a Comprehensive Cancer Center and three community oncology clinics. The Institutional Review Boards at the University of Wisconsin and other participating sites reviewed and approved the study (MR-2013-0733). All participants provided written informed consent. 
A statistician not involved in study conduct created a computerized randomization scheme. The study investigator retrieved and printed each assignment and sealed it in an opaque envelope. Upon recruitment, a research assistant (RA) provided participants with baseline questionnaires to complete at home the evening before their next chemotherapy cycle. RAs collected completed questionnaires at the next clinic visit, then opened the randomization envelope to reveal group assignment, and provided the appropriate training in the participant's chemotherapy treatment room.

An RA phoned participants weekly to remind them of study procedures and inquire about problems. Participants repeated questionnaires in their homes at 3-, 6-, and 9-weeks posttraining and returned them in a sealed envelope at the next clinic appointment.

\section{Intervention}

RAs with a Bachelor's degree in nursing, social work, or psychology, delivered the intervention training to participants. The investigator and a project manager trained interventionists following a manual that addressed background, aims, instructions for delivering the CBS intervention and cancer education training, and procedures for screening, consent, data collection, record keeping, and communication. Interventionists practiced participant training through role-play until they demonstrated satisfactory skills. With permission, participant training sessions were audio-recorded and evaluated using a fidelity checklist (see supporting information). Scores were calculated as the percentage of training activities delivered as intended. Problems were discussed at research team meetings.

CBS Intervention.-Patients assigned to the CBS intervention completed a 20-minute training session. The interventionist reviewed an educational booklet with participants, addressing (1) causes of cancer-related pain, fatigue, and sleep disturbance, (2) how the CBS intervention may affect symptoms, (3) introductions to each CBS, and (4) individualized recommendations for daily practice. Interventionists asked participants to describe what time of day their symptoms typically became bothersome, to identify appealing CBS for each symptom, and then provided suggestions to use those strategies to prevent symptom exacerbations.

Twelve CBS were provided on an MP3 player (Sony® Walkman), including three symptomfocused imagery exercises, three pleasant nature imagery exercises, three relaxation exercises, and three nature sound recordings (see supporting information). The strategies were 5 to 25 minutes in duration. None used a musical background. Participants were asked to practice at least one strategy per day, or more as needed, and log their use in a weekly diary. Participants were invited to use any or all of the strategies based on their personal preferences.

Cancer Education (Attention-Control).-Audio recordings of American Cancer Society educational materials were used to control for effects of interventionist attention and training, MP3 player novelty, and time listening to recordings. Participants assigned to the cancer education condition completed a 20-minute training session. The RA reviewed an

Psychooncology. Author manuscript; available in PMC 2019 December 01. 
educational booklet with participants addressing (1) the importance of understanding cancer and cancer treatment, (2) introductions to the cancer education recordings, and (3) individualized recommendations for listening, daily. Sixty-three unique recordings addressed basic understanding of cancer, exams and tests, treatment strategies, insurance / financial concerns, coping, and staying well (American Cancer Society, www.cancer.org). None directly addressed symptom management strategies. Recordings were approximately 5-25 minutes in duration. Participants were asked to listen to at least one recording per day, and to $\log$ their use in a weekly diary.

\section{Instruments}

Outcomes were measured at 3-, 6-, and 9-weeks post-training. Symptom cluster severity was measured with four 0-10 NRS ratings of pain ("now", "worst", "least", and "usual" in the past week $)^{27}$, four 0-10 NRS ratings of fatigue ("now", "worst", "least", and "usual" in the past week) ${ }^{28}$, and three 0-10 NRS ratings of sleep disturbance ("worst", "least", and "usual" in the past week). A composite score was created by averaging ratings within each symptom, then computing a mean across the three symptoms. Higher scores indicate greater severity. Symptom cluster distress was measured with three items from the Memorial Symptom Assessment Scale. ${ }^{29}$ Participants rated distress (bother) associated with each symptom over the past week on a 0-4 NRS. Ratings were averaged across the three symptoms. Higher scores indicate greater distress. Symptom cluster interference with daily life was measured using the Interference subscale from the MD Anderson Symptom Inventory. ${ }^{30}$ Participants rated how much their pain, fatigue, and sleep disturbance interfered with general activity, mood, work, relations with others, enjoyment of life, and ability to walk in the last week using a $0-10$ NRS. Ratings were averaged across items. Higher scores indicate greater interference (Cronbach's $a=.91-.93$ ).

Moderator variables included imaging ability and number of concurrent symptoms. The Imaging Ability Questionnaire ${ }^{24,31}$ was used to measure one's ability to create vivid mental images and experience them as if they were real (Cronbach's a=.95). Seven concurrent symptoms including nausea, vomiting, memory problems, lack of appetite, dry mouth, shortness of breath, and numbness/tingling were measured at baseline using the MD Anderson Symptom Inventory. ${ }^{30}$ A sum noted the number of symptoms present (rated $\geq 1$ ).

We evaluated four potential mediators of intervention effects, collected at baseline, 3-, 6-, and 9-weeks. The Outcome Expectancy Scale ${ }^{24,32}$ was used to measure one's belief in the efficacy of CBS (Cronbach's a=.88-.91). Higher scores indicate more positive expectancy. Perceived control over symptoms was measured with 3 items rating one's personal capacity to control pain, fatigue, and sleep disturbance. Ratings were averaged across the three items. Higher scores indicate greater perceived control. $\underline{\text { Stress }}$ was measured with the 10-item Perceived Stress Scale. ${ }^{33}$ Higher scores indicate greater perceived stress (Cronbach's a=. 84-.90). Anxiety was measured with the Profile of Mood States - Short Form TensionAnxiety subscale ${ }^{34}$; higher scores indicate greater anxiety (Cronbach's $a=.90-.93$ ).

Demographic and clinical characteristics were collected from patient self-report and medical records. Depression was measured using the Center for Epidemiologic Studies - Depression (CES-D) questionnaire ${ }^{35}$; scores $\geq 16$ suggest possible depression (Cronbach's $a=.86$ ). 
Participants logged their use of study recordings and other steps taken to control pain, fatigue, and sleep disturbance in a weekly diary. At the 9-week visit, participants completed an 8-item post-study evaluation of the assigned recordings.

\section{Data Analyses}

Data were analyzed using SPSS version 23. An intent-to-treat (ITT) analysis was planned. Missing data were replaced using the SPSS multiple imputation algorithm (averaging $m=5$ imputed datasets). We tested hypotheses using Analysis of Covariance including design factors (recruitment site, diagnosis, gender, and chemotherapy cycle length) and covariates (age, education, depression, number of supportive medications) related to symptom experience and reporting ${ }^{36-37}$. All analyses and covariates were pre-specified. One-tailed tests were used to evaluate directional hypotheses.

\section{Results}

\section{Sample Characteristics}

A total of 188 patients were eligible and enrolled. Twenty-four withdrew before randomization; 164 were randomized ( $\mathrm{n}=85 \mathrm{CBS}$ intervention, $\mathrm{n}=79$ attention-control). Three were excluded from analyses due to mistakes in study procedures (e.g., intervention delivered before completing the baseline questionnaire) (Figure 1).

Participants were predominantly female, Caucasian, non-Hispanic, and had some college education (Table 1). Most had breast, lung, or gastrointestinal cancers, and were receiving cytotoxic chemotherapy in 3-week cycles. Participants were prescribed an average of five types of supportive medications for symptom management. Baseline symptom cluster scores were similar in the CBS intervention versus cancer education groups.

Mean interventionist fidelity scores were $91 \%$ for both the intervention and control groups. Participants' weekly use of CBS ranged from a high of $\mathrm{M}=10.30$ (week 1) to a low of $M=7.52$ (week 9). In the control group, participants used a high of $M=10.15$ (week 1) to a low of $\mathrm{M}=5.61$ (week 8) cancer education recordings per week.

\section{Intervention Efficacy (Table 2)}

Symptom cluster severity scores did not differ by group at weeks 3, 6, or 9. Symptom cluster distress scores did not differ by group at weeks 3 or 9 , however at week 6 , the CBS intervention group reported lower symptom cluster distress scores $\left(\mathrm{M}_{\mathrm{Adj}}=1.82\right)$ compared to the control group $\left(\mathrm{M}_{\mathrm{Adj}}=2.15\right) \mathrm{F}(1,130)=3.04, \mathrm{p}=.04$. Symptom cluster interference did not differ by group at any follow-up point.

\section{Moderators of Treatment Effects}

We tested potential group-by-imaging ability and group-by-number of concurrent symptoms interactions. Imaging ability did not moderate intervention effects for any outcomes at any follow-up point. Number of concurrent symptoms did not moderate intervention effects on symptom cluster severity or distress at week 3,6 , or 9. It did, however, moderate intervention effects on symptom cluster interference at weeks 6 and 9. At lower numbers of 
concurrent symptoms, the CBS intervention was more effective than cancer education in controlling symptom cluster interference, whereas there was little difference between groups at higher numbers of concurrent symptoms [week $6, \mathrm{~F}(1,126)=3.88, \mathrm{p}=.03$; week 9 , $\mathrm{F}(1,126)=4.47, \mathrm{p}=.02]$.

\section{Mediators of Treatment Effects}

We evaluated mediation for all outcomes, given that suppression or dilution may explain non-significant treatment effects. ${ }^{38}$ Following the test of joint significance ${ }^{39}$, the intervention-mediator path was examined to determine the effect of treatment group on change in the mediating variable from baseline. If this path was significant, the mediatoroutcome path was tested to determine if change in the mediating variable influenced symptom cluster outcomes. Mediation is considered present if both paths are significant.

None of the mediating relationships were significant at the 3-week follow-up point, but several were significant at weeks 6 and 9 (Figures 2a-2c). Change in stress differed by group at week $9[\mathrm{~F}(1,130)=2.90, \mathrm{p}=.04]$, with greater reductions in stress in the treatment versus control group. This change in stress predicted lower symptom cluster severity, distress, and interference; mediating all three outcomes at 9-weeks post-intervention \{ severity $[F(1,128)=22.18, p<.01]$; distress $[F(1,128)=15.05, \mathrm{p}<.01]$; interference $[F(1,128)=72.03$, $\mathrm{p}<.01]\}$. Change in anxiety did not differ by treatment group at any follow-up point.

Change in outcome expectancy differed by group at weeks $6[\mathrm{~F}(1,130)=5.46, \mathrm{p}=.01]$ and 9 $[\mathrm{F}(1,130)=3.45, \mathrm{p}=.03]$, with larger improvements in the treatment versus control group. This change predicted lower symptom cluster interference, mediating treatment effects at weeks $6[\mathrm{~F}(1,128)=2.93, \mathrm{p}=.04]$ and $9[\mathrm{~F}(1,128)=4.75, \mathrm{p}=.01]$. Change in perceived control over symptoms differed by treatment group at weeks $6[\mathrm{~F}(1,130)=6.75, \mathrm{p}<.01]$ and 9 $[F(1,130)=3.28, p=.03]$, with greater improvement in perceived control in the treatment versus control group. This change predicted all three symptom cluster outcomes, mediating treatment effects at weeks 6 and 9 \{week 6: severity $[\mathrm{F}(1,128)=27.88, \mathrm{p}<.01]$, distress $[F(1,128)=24.98, \mathrm{p}<.01]$, interference $[\mathrm{F}(1,128)=19.31, \mathrm{p}<.01]$; week 9 : severity $[F(1,128)=33.25, p<.01]$, distress $[F(1,128)=17.40, p<.01]$, interference $[F(1,128)=16.48$, $\mathrm{p}<.01]\}$.

\section{Participant Evaluation}

Compared to the cancer education group, more CBS intervention participants indicated they enjoyed using the recordings (67\% vs. $36 \%$ ), learned something useful (61\% vs. $28 \%$ ), and perceived improvement in their symptoms (65\% vs. $18 \%$ ), with moderate or greater symptom relief ( $49 \%$ vs. 19\%), and improved feelings of control over symptoms (46\% vs. $24 \%$ ). Using a 0-10 scale, CBS intervention participants reported higher levels of distraction $(\mathrm{M}=5.79$ vs. $\mathrm{M}=2.81)$ and relaxation $(\mathrm{M}=6.58$ vs. $\mathrm{M}=2.80)$ than those receiving cancer education. Negative reactions, including anxiety, sadness, unpleasant thoughts, boredom, and irritation, were reported by $11 \%$ of the CBS intervention group and by $21 \%$ of those receiving cancer education. 


\section{Discussion}

This study is among the first to test an intervention targeting a specific symptom cluster. The CBS intervention demonstrated some improvement in symptom cluster distress, but minimal effects on severity and interference with life. Observed means were in the expected direction and many participants perceived symptom improvement and enhanced control.

Current findings are less robust than benefits observed in our pilot work ${ }^{12}$. Consistent with our findings, Mosher and colleagues ${ }^{40}$ reported limited improvement in lung cancer-related pain, fatigue, and breathlessness with training in cognitive-behavioral and emotion-focused symptom coping strategies (including relaxation and imagery) as compared to education and support. Our findings contrast with a recent trial demonstrating that a 4-week imagery and relaxation intervention reduced pain and fatigue in the context of a cancer symptom cluster (pain, fatigue, nausea, vomiting, anxiety, and depression). ${ }^{41}$ However, their intervention included music as an additional active component, and was evaluated in patients with early stage, non-metastatic cancer. ${ }^{41}$ Previous studies also compared CBS interventions to less rigorous, usual care control groups ${ }^{12,41}$ Although they provide a stronger test of efficacy, attention control activities may mask symptom worsening typically observed over time in persons with advanced disease. Trials using a 3-arm design (active treatment, attentioncontrol, usual care) could help clarify intervention efficacy.

We intended for the brief CBS intervention to be rapidly implemented in response to symptom escalation, similar to rescue medications for breakthrough pain. Patients may have experienced meaningful short-term benefits that were not captured by our outcome measurement schedule. Positive post-study evaluations describing moderate or greater improvement in the symptom experience support this possibility, despite an absence of sustained effects over time. Future studies might use ecological momentary assessment to capture immediate effects of the CBS intervention, although response burden may preclude successful use in advanced cancer populations.

Effects observed at week 6 were not maintained at the 9-week data collection point. Perhaps illness progression led to a worsening of symptoms, or participants grew tired of using the same exercises over time. Indeed, fewer uses were reported at week 9 than week 1, although in post hoc analyses, frequency of recording use did not moderate intervention effects. Future research should evaluate these potential explanations.

The study provides several important contributions with respect to hypothesized mediators as mechanisms of CBS intervention benefits. Improvements in stress, outcome expectancy, and perceived control were observed in the CBS intervention group, and were associated with reductions in symptom cluster severity, distress, and interference. For patients with advanced disease, the use of brief CBS interventions may be more feasible than traditional multicomponent, multi-session cognitive-behavioral therapy, but not be as effective. Mediation analyses suggest the CBS intervention may be strengthened by adding strategies that further impact stress, outcome expectancy, and perceived control, or that work via complementary pathways such as increased physical activity. 


\section{Study Limitations}

Symptom cluster severity was mild-to-moderate at baseline, contributing to floor effects. We used a heterogeneous sample of patients with different diagnoses and cancer treatment protocols. While symptom management guidelines typically do not differ by cancer diagnoses, variation in chemotherapy toxicities may have influenced observed outcomes. In addition, our sample may be slightly biased toward persons on 3-week IV chemotherapy regimens due to our eligibility expansion. Our attention-control condition may have provided an engaging source of distraction, or elicited relaxation through the soothing nature of the narrator's voice. In addition, education could have empowered patients to feel more confident in self-advocating for symptom management needs. Type I error rate was not divided among multiple tests in exploratory week 6 and 9 analyses. Lastly, excluding data from 3 participants where there were mistakes in study procedures could be considered a violation of ITT.

\section{Clinical Implications}

The CBS intervention may provide some small therapeutic benefit for patients experiencing co-occurring pain, fatigue, and sleep disturbance. Clinicians can encourage self-management of this symptom cluster by identifying strategies that reduce stress, enhance positive expectations, and foster perceptions of personal control over symptoms. Future research should seek to reduce self-management burden and improve palliative care for patients by developing efficient symptom cluster interventions using focused strategies that help to ameliorate multiple co-occurring symptoms.

\section{Supplementary Material}

Refer to Web version on PubMed Central for supplementary material.

\section{Acknowledgements:}

This work was supported by the National Institute of Nursing Research of the National Institutes of Health (NIH) under award R01NR013468. The content is solely the responsibility of the authors and does not necessarily represent the official views of the NIH. The authors acknowledge collaboration of James Cleary, MD, shared research resources of the University of Wisconsin Carbone Cancer Center, and educational materials used with permission of the American Cancer Society. We also thank the patients and families who participated in this research.

\section{References}

1. Reilly CM, Bruner DW, Mitchell SA, Minansian LM, Basch E, Dueck AC, et al. A literature synthesis of symptom prevalence and severity in persons receiving active cancer treatment. Support Care Cancer 2013 6;21(6):1525-1550. [PubMed: 23314601]

2. Kirkova J, Walsh D, Rybicki L, Davis MP, Aktas A, Jin T, et al. Symptom severity and distress in advanced cancer. Pall Med, 2010 4; 24(3):330-339.

3. Beck SL, Dudley WN, Barsevick A. Pain, sleep disturbance, and fatigue in patients with cancer: Using a mediation model to test a symptom cluster. Oncol Nurs Forum 20055 10;32(3):E48-55.

4. Cheng KKF, Lee DTF. Effects of pain, fatigue, insomnia, and mood disturbance on functional status and quality of life of elderly patients with cancer. Crit Rev Oncol Hematol 2011 5;78(2):127-137. [PubMed: 20403706]

5. Dodd MJ, Miaskowski C, Paul SM. Symptom clusters and their effect on the functional status of patients with cancer. Oncol Nurs Forum 2001 4;28(3):465-470. [PubMed: 11338755] 
6. Hoffman AJ, Given BA, Von Eye A, Gift AG, Given CW. Relationships among pain, fatigue, insomnia, and gender in persons with lung cancer. Oncol Nurs Forum 2007 7;34(4):785-792. [PubMed: 17723980]

7. Miaskowski C, Barsevick A, Berger A, Casagrande R, Grady PA, Jacobsen P, et al. Advancing symptom science through symptom cluster research: Expert panel proceedings and recommendations. J Natl Cancer Inst 20171 24;109(4):1-9.

8. Miller AH, Ancoli-Israel S, Bower JE, Capuron L, Irwin MR. Neuroendocrine-immune mechanisms of behavioral comorbidities in patients with cancer. J Clin Oncol 20082 20;26(6):971-982. [PubMed: 18281672]

9. Wood LJ, Weymann K. Inflammation and neural signaling: Etiologic mechanisms of the cancer treatment-related symptom cluster. Curr Opin Support Palliat Care 20133 1;7(1):54-59. [PubMed: 23314015]

10. Chan CWH, Richardson A, Richardson J. Managing symptoms in patients with advanced lung cancer during radiotherapy: Results of a psychoeducational randomized controlled trial. J Pain Symptom Manage 2011 2;41(2):347-357. [PubMed: 21131165]

11. Kwekkeboom KL, Abbott-Anderson K, Wanta B. Feasibility of a patient-controlled cognitivebehavioral intervention for pain, fatigue, and sleep disturbance in cancer. Oncol Nurs Forum 2010 5;37(3):E151-E159. [PubMed: 20439200]

12. Kwekkeboom KL, Abbott-Anderson K, Cherwin C, Roiland R, Serlin RC, Ward SE. Pilot randomized controlled trial of a patient-controlled cognitive-behavioral intervention for the pain, fatigue, and sleep disturbance symptom cluster in cancer. J Pain Symptom Manage 2012 12;44(6): 810-822. [PubMed: 22771125]

13. Milandania M, Baraz S, Shariati A, Malehi AS. Effects of slow-stroke back massage on symptom cluster in adult patients with acute leukemia: Supportive care in cancer nursing. Cancer Nurs 2017 Jan-Feb;40(1):31-38. [PubMed: 26925992]

14. Tarrasch R, Carmel-Neiderman NN, Ben-Ami S, Kaufman B, Pfeffer R, Ben-David M, et al. The effect of reflexology on the pain-insomnia-fatigue disturbance cluster of breast cancer patients during adjuvant radiation therapy. J Altern Complement Med 2018 1;24(1):62-68. [PubMed: 28440664]

15. Yeh CH, Chien L, Lin W, Bovbjerg DH, van Londen GJ. Pilot randomized controlled trial of auricular point acupressure to manage symptom clusters of pain, fatigue, and disturbed sleep in breast cancer. Cancer Nurs 2016 Sep-Oct;39(5):402-410. [PubMed: 26390073]

16. Yorke J, Lloyd-Williams M, Smith J, Blackhall F, Harle A, Warden J, et al. Management of the respiratory distress symptom cluster in lung cancer: A randomized controlled feasibility trial. Support Care Cancer 2015 11;23(11):3373-3384. [PubMed: 26111954]

17. American Pain Society. Guidelines for the management of cancer pain in adults and children Glenview, IL: American Pain Society; 2004.

18. National Comprehensive Cancer Network (NCCN). NCCN clinical practice guidelines in oncology: Adult cancer pain, Version 2 [Internet]. 2017 [cited 2017 Sep 20]. Available from: www.ncen.org

19. National Comprehensive Cancer Network (NCCN). NCCN Clinical Practice Guidelines in Oncology: Cancer-Related Fatigue, Version 2 [Internet]. 2017 [cited Sep 20]. Available from www.ncen.org

20. Oncology Nursing Society. Putting Evidence Into Practice: Sleep Wake Disturbances [Internet]. Pittsburg, PA: Oncology Nursing Society; 2017 [cited Sep 20]. Available from: https:// www.ons.org/practiceresources/pep/sleep-wake-disturbances

21. National Cancer Institute. Sleep Disorders (PDQ) - Health Professional Version [Internet] Bethesda, MD: National Cancer Institute; 2016 [cited 2017 Sep 20]. Available from: https:// www.cancer.gov/about-cancer/treatment/side-effects/sleep-disorders-hp-pdq\#section/all

22. Jensen M Psychosocial approaches to pain management: An organizational framework. Pain 2011 4;152(4):717-725. [PubMed: 21168972]

23. Kwekkeboom K, Cherwin C, Lee JW, and Wanta B. Mind-body treatments for the pain-fatiguesleep disturbance symptom cluster in persons with cancer. J Pain Symptom Manage 2010 1;39(1): 126-138. [PubMed: 19900778] 
24. Kwekkeboom KL, Wanta B, Bumpus M. Individual difference variables and the effects of progressive muscle relaxation and analgesic imagery interventions on cancer pain. J Pain Symptom Manage 200812 28;36(6):604-615. [PubMed: 18504089]

25. Kwekkeboom KL, Kneip J, Pearson L. A pilot study to predict success with guided imagery for cancer pain. Pain Manag Nurs 2003 9;4(3):112-123. [PubMed: 14566709]

26. Portenoy R Development and testing of a neuropathic pain screening questionnaire: ID Pain. Curr Med Res Opin 2006 8;22(8):1555-1565. [PubMed: 16870080]

27. Cleeland CS. Measurement of pain by subjective report. In: Chapman CR, Loeser JD, editors. Issues in Pain Management New York: Raven Press; 1989 p. 391-403.

28. Mendoza TR, Wang XS, Cleeland CS, Morrissey M, Johnson BA, Wendt JK, et al. The rapid assessment of fatigue severity in cancer patients: Use of the brief fatigue inventory. Cancer 1999 3;85(5):1186-1196. [PubMed: 10091805]

29. Portenoy RK, Thaler HT, Kornblith AB, Leport JM, Friedlander-Klar H, Kiyasu E, et al. The Memorial Symptom Assessment Scale: An instrument for the evaluation of symptom prevalence, characteristics, and distress. Eur J Cancer 1994;30A(9):1326-1336. [PubMed: 7999421]

30. Cleeland CS, Mendoza TR, Wang XS, Chou C, Harle M, Morrissey M, et al. Assessing symptom distress in cancer: The M. D. Anderson symptom inventory. Cancer 200010 1;89(7):1634-1646. [PubMed: 11013380]

31. Kwekkeboom KL. Measuring imaging ability: Psychometric testing of the imaging ability questionnaire. Res Nurs Health 2000 8;23(4):301-309. [PubMed: 10940955]

32. Kwekkeboom KL. Outcome expectancy and success with cognitive-behavioral interventions: The case of guided imagery. Oncol Nurs Forum 2001 8;28(7):1125-1132. [PubMed: 11517846]

33. Cohen S, Williamson G. Perceived stress in a probability sample of the United States. In: Spacapan S, Oskamp S, editors. The social psychology of health: Claremone Symposium on applied social psychology Newbury Park, CA: Sage; 1988 p. 31-67.

34. Shacham S A shortened version of the profile of mood states. J Pers Assess 1983 6;47(3):305-306. [PubMed: 6886962]

35. Radloff LS. The CES-D scale: A self-report depression scale for research in the general population. Appl Psych Meas 19776 1;1(3):385-401.

36. Delgado-Guay M, Parsons HA, Li Z, Palmer JL, Bruera E. Symptom distress in advanced cancer patients with anxiety and depression in the palliative care setting. Support Care Cancer 2009 5;17(5):573-579. [PubMed: 19005686]

37. Lloyd-Williams M, Dennis M, Taylor F. A prospective study to determine the association between physical symptoms and depression in patients with advanced cancer. Palliat Med 2004 9;18(6): 558-563. [PubMed: 15453627]

38. Krause MR, Serlin RC, Ward SE, Rony Y, Ezenwa M, Naab F. Testing mediation in nursing research: Beyond Baron and Kenny. Nurs Res 2010 Jul-Aug;59(4):288-294. [PubMed: 20467337]

39. MacKinnon DP, Lockwood CM, Hoffman JM, West SG, Sheets V. A comparison of methods to test mediation and other intervening variable effects. Psychol Methods 2002 3;7(1):83-104. [PubMed: 11928892]

40. Mosher E, Winger JG, Hanna N, Jalal SI, Einhorn LH, Birdas TJ, et al. Randomized pilot trial of a telephone symptom management intervention for symptomatic lung cancer patients and their family caregivers. J Pain Symptom Manage 2016 10;52(4):469-482. [PubMed: 27401514]

41. Charalambous A, Giannakopoulou M, Bozas E, Marcou Y, Kitsios P, Paikousis L. Guided imagery and progressive muscle relaxation as a cluster of symptoms management intervention in patients receiving chemotherapy: A randomized controlled trial. PLOS ONE [Internet] 2016 June. Available from: http://journals.plos.org/plosone/article?id=10.1371/journal.pone.0156911 DOI: http://journals.plos.org/plosone/article?id=10.1371/journal.pone.015691110.137/journal.pone. 0156911 DOI: 10.137/journal.pone.0156911 


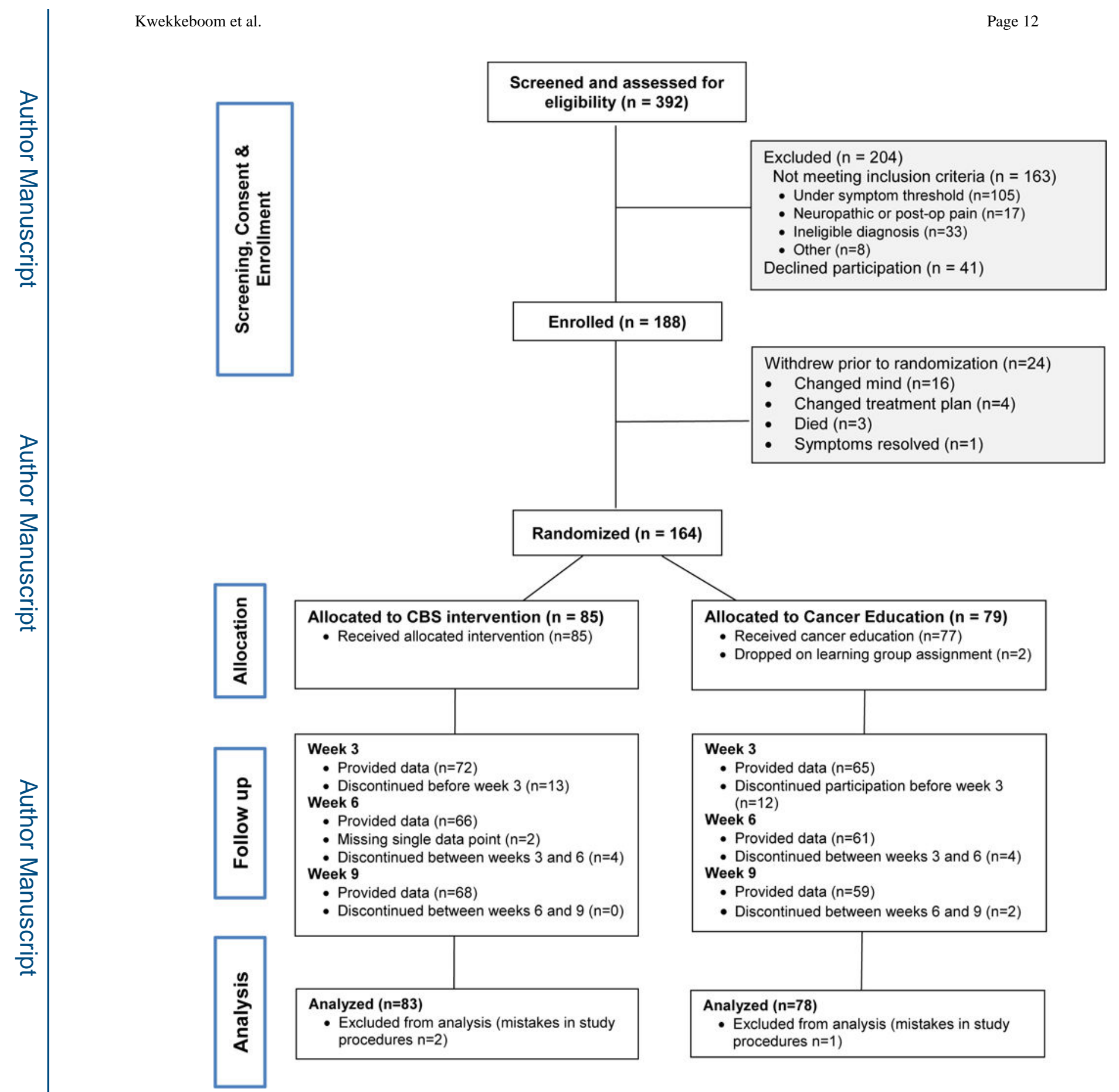

Figure 1.

Participant Flow Diagram 
2a. Mediation by Change in Stress (Week 9)

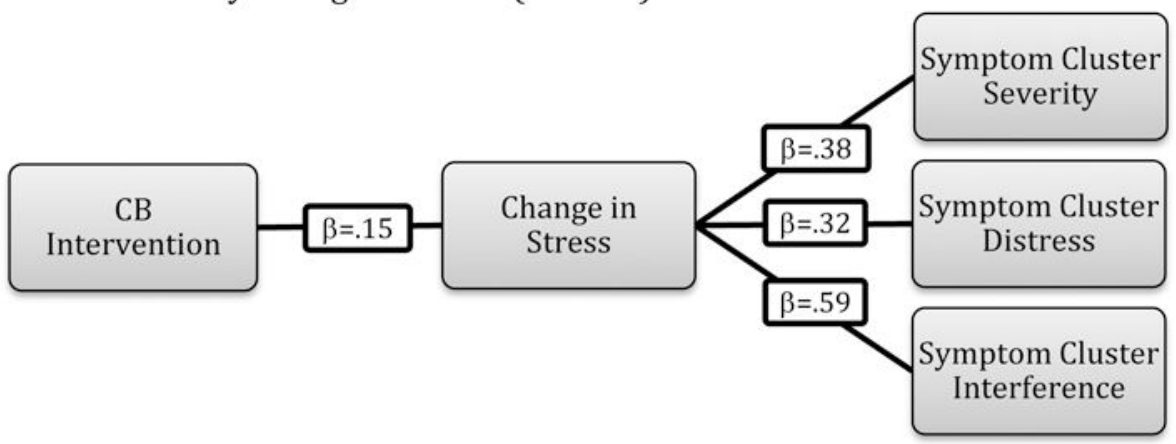

2b. Mediation by Change in Outcome Expectancy (Week $6 \&$ 9)*

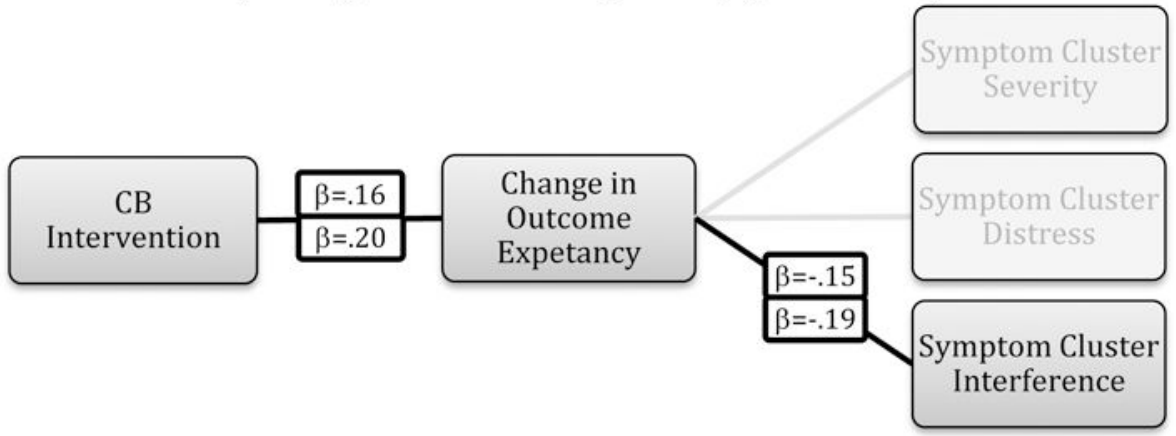

2c. Mediation by Change in Perceived Control (Week $6 \& 9$ )*

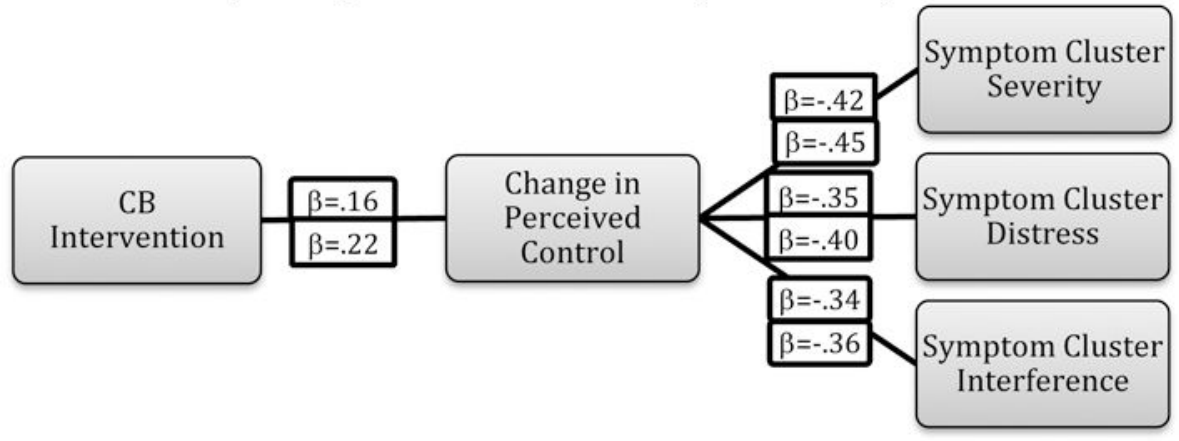

${ }^{*}$ Upper boxes $=\beta$ week $6 ;$ lower boxes $=\beta$ week 9

Figure 2a-c.

Mediators of Intervention Effects on Symptom Cluster Outcomes

Psychooncology. Author manuscript; available in PMC 2019 December 01. 


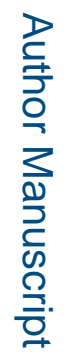

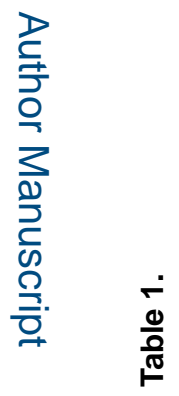

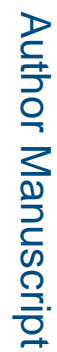

\begin{tabular}{|c|c|c|c|c|c|c|c|c|c|c|c|c|}
\hline \multirow{2}{*}{ 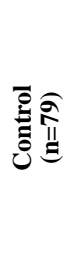 } & 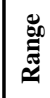 & $\begin{array}{l}n \\
\hat{i} \\
o \\
q\end{array}$ & $\frac{0}{1}$ & $\begin{array}{l}1 \\
\infty \\
\infty \\
\infty \\
0\end{array}$ & $\begin{array}{l}1.8 \\
60 \\
0 .+\end{array}$ & $\begin{array}{l}18 \\
100 \\
0\end{array}$ & \multirow[b]{2}{*}{ of } & \multirow{2}{*}{ 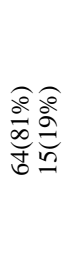 } & \multirow{2}{*}{ 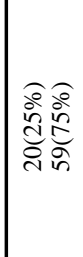 } & \multirow{2}{*}{ 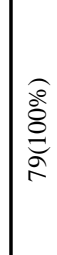 } & \multirow{2}{*}{ 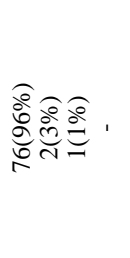 } & \multirow{2}{*}{ 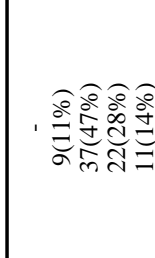 } \\
\hline & $\widehat{\text { क्रे }}$ & 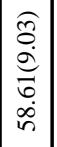 & 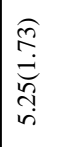 & 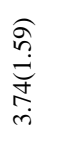 & 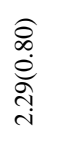 & $\begin{array}{l}\stackrel{6}{\mathfrak{d}} \\
\stackrel{+}{+} \\
\dot{q}\end{array}$ & & & & & & \\
\hline \multirow{2}{*}{ 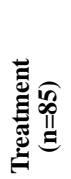 } & 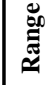 & $\begin{array}{l}\hat{i} \\
\grave{i}\end{array}$ & ì & $\begin{array}{l}18 \\
50 \\
0\end{array}$ & $\begin{array}{l}18 \\
\\
0\end{array}$ & $\begin{array}{l}18 \\
-10 \\
0\end{array}$ & \multirow[b]{2}{*}{$\stackrel{Ð}{=}$} & \multirow{2}{*}{ 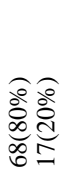 } & \multirow{2}{*}{ 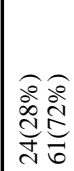 } & \multirow{2}{*}{\begin{tabular}{l}
$\widehat{0}$ \\
$\stackrel{0}{o}$ \\
\multirow{2}{\infty}{}
\end{tabular}} & \multirow{2}{*}{ 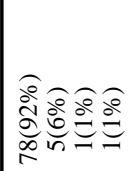 } & \multirow{2}{*}{ 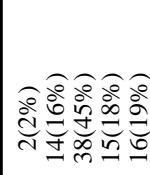 } \\
\hline & $\widehat{0}$ & $\left|\begin{array}{c}\hat{\curvearrowright} \\
\stackrel{\alpha}{\varrho}\end{array}\right|$ & $\underset{\hat{G}}{\mathrm{G}}$ & 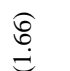 & $\widehat{\widehat{\sigma}}$ & $\underset{\mathrm{N}}{\mathbb{N}}$ & & & & & & \\
\hline
\end{tabular}

롤

\begin{tabular}{|c|c|c|c|c|c|c|c|c|c|c|c|c|}
\hline 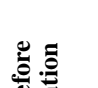 & 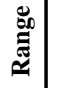 & $\begin{array}{l}\stackrel{\vartheta}{1} \\
\vec{m}\end{array}$ & $\begin{array}{l}\infty \\
m \\
m\end{array}$ & & & & \multirow[b]{2}{*}{$\stackrel{\varrho}{g}$} & \multirow[b]{2}{*}{ 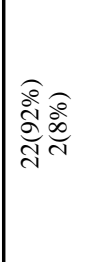 } & \multirow[b]{2}{*}{ 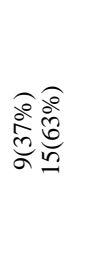 } & \multirow[b]{2}{*}{ 产 } & \multirow[b]{2}{*}{ 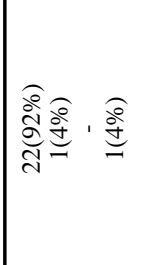 } & \multirow[b]{2}{*}{, } \\
\hline 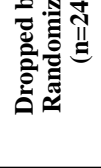 & $\widehat{\widehat{\hat{t}}}$ & 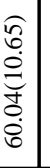 & 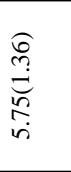 & & & & & & & & & \\
\hline \multirow{3}{*}{ 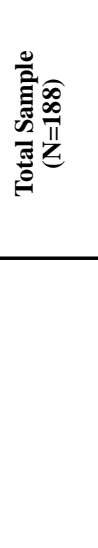 } & 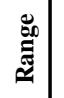 & $\begin{array}{l}\hat{\imath} \\
\text { ते }\end{array}$ & $\begin{array}{l}0 \\
\stackrel{1}{1}\end{array}$ & & & & \multirow{2}{*}{$\stackrel{\varrho}{g}$} & \multirow{2}{*}{ 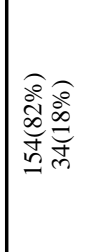 } & \multirow{2}{*}{ 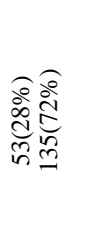 } & \multirow{2}{*}{ 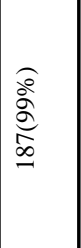 } & \multirow{2}{*}{ 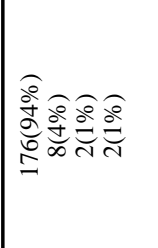 } & \multirow{2}{*}{ 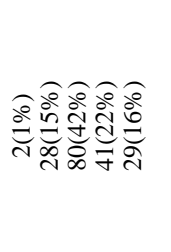 } \\
\hline & $\widehat{\widehat{c}}$ & 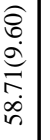 & $\begin{array}{l}\text { है } \\
\stackrel{\Xi}{ \pm} \\
\text { in } \\
\text { in }\end{array}$ & & & & & & & & & \\
\hline & & 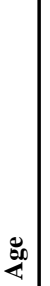 & 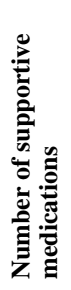 & 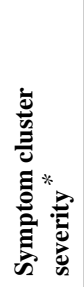 & 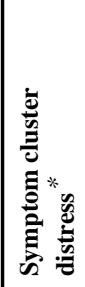 & 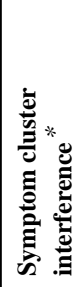 & & 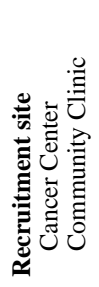 & 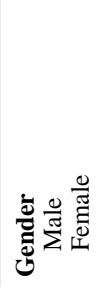 & 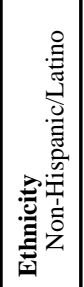 & 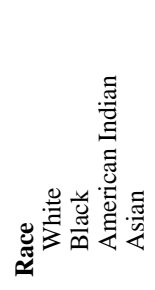 & 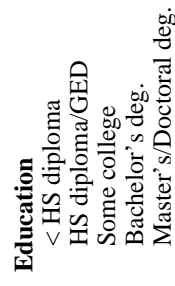 \\
\hline
\end{tabular}

Psychooncology. Author manuscript; available in PMC 2019 December 01. 


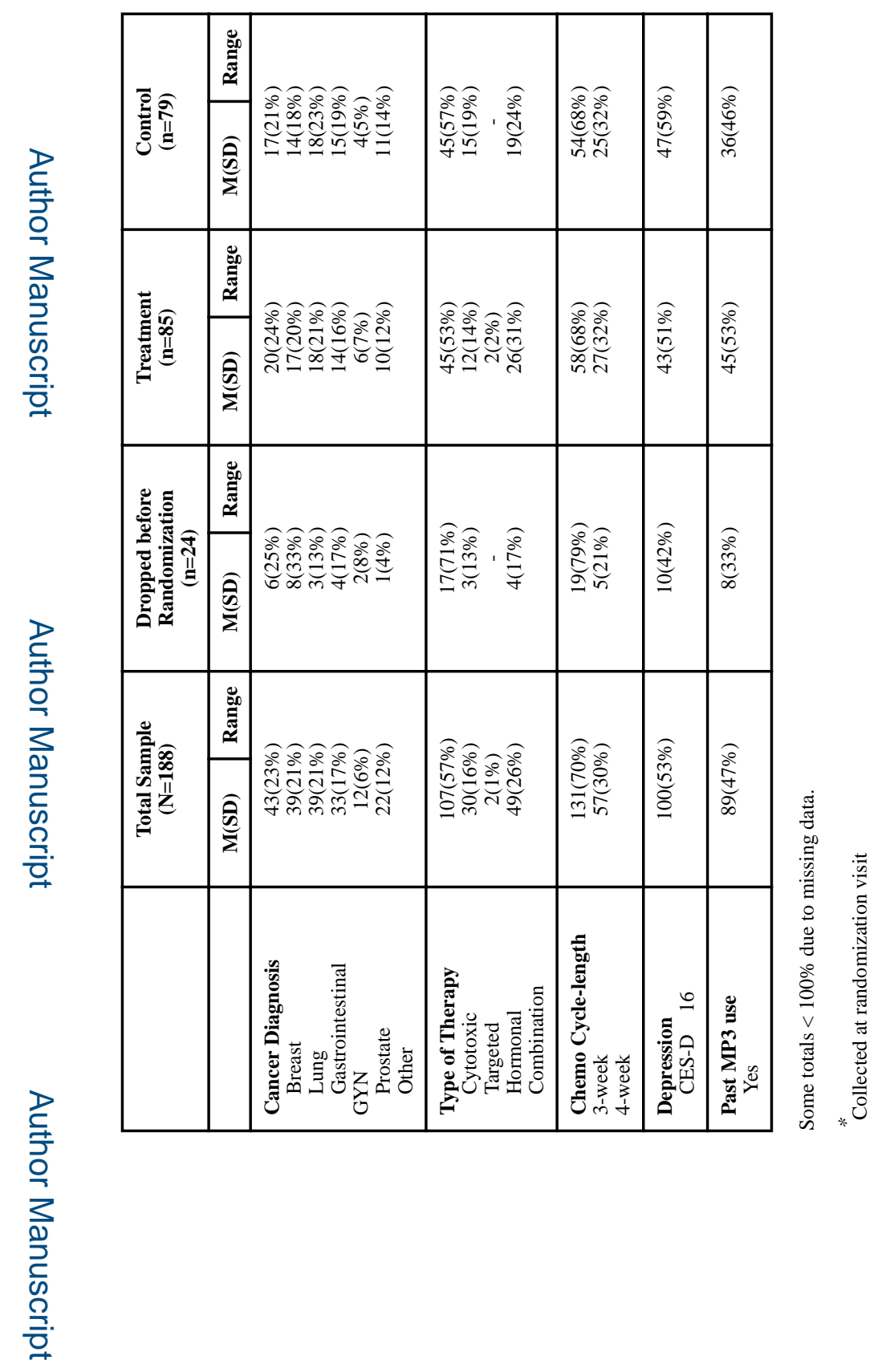

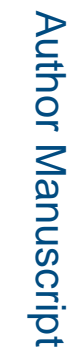


Table 2.

Adjusted Mean (SD) Symptom Cluster Outcomes by Group and Time (N=161)

\begin{tabular}{|c|c|c|c|c|}
\hline & $\begin{array}{c}\text { CBS Intervention } \\
\left.\mathbf{M}_{\text {Adj }} \mathbf{9 5 \%} \mathbf{~ C I}\right)\end{array}$ & $\begin{array}{c}\text { Attention-Control } \\
\mathbf{M}_{\text {Adj }}(\mathbf{9 5 \%} \mathbf{C I})\end{array}$ & $\begin{array}{c}\text { Adjusted Mean } \\
\text { Difference } \\
\mathbf{9 5 \%} \mathbf{C I})\end{array}$ & $\begin{array}{c}\text { p-value } \\
\text { (1-tailed) }\end{array}$ \\
\hline $\begin{array}{l}\text { Symptom } \\
\text { Cluster Severity }\end{array}$ & & & & \\
\hline Week 3 & $3.55(3.11,4.00)$ & $3.74(3.34,4.14)$ & $-.19(-.74, .36)$ & .25 \\
\hline Week 6 & $3.61(3.06,4.15)$ & $3.71(3.22,4.20)$ & $-.11(-.78, .57)$ & .38 \\
\hline Week 9 & $3.36(2.80,3.91)$ & $3.71(3.21,4.21)$ & $-.36(-1.04, .33)$ & .15 \\
\hline $\begin{array}{l}\text { Symptom } \\
\text { Cluster Distress }\end{array}$ & & & & \\
\hline Week 3 & $1.94(1.67,2.21)$ & $2.07(1.83,2.31)$ & $-.13(-.46, .20)$ & .22 \\
\hline Week 6 & $1.82(1.52,2.12)$ & $2.15(1.88,2.42)$ & $-.33(-.70, .04)$ & .04 \\
\hline Week 9 & $1.87(1.57,2.16)$ & $1.99(1.72,2.26)$ & $-.12(-.49, .25)$ & .26 \\
\hline $\begin{array}{l}\text { Symptom } \\
\text { Cluster } \\
\text { Interference }\end{array}$ & & & & .14 \\
\hline Week 3 & $3.97(3.22,4.71)$ & $4.48(3.79,5.16)$ & $-.51(-1.45, .42)$ & .14 \\
\hline Week 6 & $3.68(2.99,4.37)$ & $4.25(3.62,4.89)$ & $-.57(-1.44, .30)$ & .10 \\
\hline Week 9 & $3.83(3.04,4.62)$ & $4.15(3.42,4.88)$ & $-.32(-1.31, .67)$ & .26 \\
\hline
\end{tabular}

Adjusted for baseline score, age, education, depression, and number of supportive medications 